\title{
Interactive comment on "Combinatorial observation ionospheric characteristics during tropical cyclone Debbie passing eastern Australia in 2017 using GPS and ion sounder” by Fuyang Ke et al.
}

\section{Anonymous Referee \#1}

Received and published: 2 August 2019

The authors reported a multi-instrument experiment to study the effects of tropospheric cyclone on overlying ionosphere. The topic corresponds to the profile of the journal. The topic is relevant since there are still many open questions in connection with the troposphere - upper atmosphere/ionosphere coupling mechanisms. The present study investigated the ionospheric response to tropical cyclone named DEBBIE passing over eastern Australia using GPS and ionosonde data. The processes within the ionosphere was very complex, since the investigated meteorological event occurred during the main and recovery phase of a moderate geomagnetic storm. Therefore, this is 
an interesting event to investigate its impact on the ionosphere. However, the authors needs to complete the introduction part and deepen the physical discussions of the observed results. Therefore, the authors need to improve significant modifications. Furthermore, the authors need to improve English significantly. Thus, I suggest a major revision before the acceptance of the manuscript to publish. General comments: 1.) The authors called in different strange names the ionosondes: e.g. "The stronger enhancement of fOF1 and fOF2 was observed by High Frequency at" and "ion sounder" in the title, abstract and in the whole text. I suggest to use the further expressions to name this instrument: High Frequency radio sounder or ionosonde. 2.) The English of the whole text have to be improved. Please, use the same, past or present tense during the whole manuscript. Take care of the word order of the sentences, check singular/plural, furthermore the prepositions. Avoid the repetition of a word. 3.) Introduction: In the discussion part the author count the different coupling mechanisms but they didn't detail them in the introduction. Please, write 1-2 paragraphs about the different mechanisms what you listed in the discussion with more reference. 4.) Page 2 line 50: I miss a reference in connection with the hurricanes in Czech republic: "the results of statistical analysis showed that ionospheric disturbance percentage of 24 strong typhoons in China (Xiao et al., 2007), 41 tropical cyclones in the Atlantic Ocean (Nina et al., 2017), and 25 hurricanes in western and central part of the 50 Czech Republic were $92 \%, 88 \%$ and $8 \%$, respectively" 5.) Page 3 Fig. 1 and its caption: Why do you indicate the same type of symbol more times on the Figure? Caption: I only see blue stars and one arrow and one red pentagram on the Figure. Please, correct the caption. 6.) Page 3 line 80 and more times after that: "the wind speed of $105 \mathrm{~m} / \mathrm{s}$ " Are you sure in this data? $105 \mathrm{~m} / \mathrm{s}=378 \mathrm{~km} / \mathrm{h}$ ! 7.) Page 4 line 89-91: This sentence is a little bit confusing: "The shortest distances from the tropical cyclone center to these stations above were $160 \mathrm{~km}$ at UT00:00 of 24 March 2017, $230 \mathrm{~km}$ at UT00:00 of 28 March 2017, $167 \mathrm{~km}$ at UT12:00 of 29 March 2017, $230 \mathrm{~km}$ at UT00:00 of 2890 March 2017 and $925 \mathrm{~km}$ at UT12:00 of 30 March 2017, respectively." It would be better the define the distance station by station. 9.) Page 6 line 148 and Fig. 3.: What was the 
exact time when Debbie landed on Hook Island? I can see more increase on 27 Mach also in ROT for PRN01 and PRN11. 10.) About the 4.1 and 4.2 subsections and Fig 3 and 4.: It would be nice to see a measurement of a reference satellite for away from the cyclone. 11.) Fig. 5.: I can see more red point north from the red circle but at the same longitude. Can you detail the reason of those red dots/anomalies? 12.) In connection with subsection 4.3: Why don't you use the monthly median or an average of reference days (geomagnetically quiet days) as reference and compare it with ionospheric parameters (foE, foF2, foF1) observed during the investigated period? If you use: "best fits for their mean value from 24 to 31 March ... as their normal values" you use the parameters observed during geomagnetically disturbed period as reference. Thus I suggest to repeat the analysis using the monthly median of the parameters or detected during geomagnetically calm periods. 13.) Fig. 8. What does the pink rectangular good for? Please, detail it in the caption of the figure. 14.) Page 10. line 217: "The electron density ðiŚĄðiśŠ is linear related to fOF1 and fOF2." It is not true. Look at the eq. (4) at the manuscript. 15.) Page 10. line 220: "Therefore, the stronger fOF1 and f0F2 enhancement of Townsville station on 28 March should be attributed to tropical cyclone Debbie". I can see strong foF1 variation also at Brisbane. How can you explain it? 16.) Discussion: The discussion is very short. In the first paragraph the authors count the different coupling mechanisms. But they didn't discuss them and didn't compare them with their findings. They say that the morphological characteristic of the ionospheric variations what they found agree only one mechanism of them (turbulent top movement) but they didn't explain why. Please, discuss you results more carefully and compare them with the findings of previous studies in the literature. Especially detail please the last 4 lines of the discussion, the mechanism in connection with the generation of the plasma bubbles.

Minor comments: - The title of 4.3 subsection: "4.3 The ionospheric parameters in E/F1/F2 layer by ion sounder" change it to e.g.: "4.3 The ionospheric parameters in E/F1/F2 layer detected by ionosondes" or " 4.3 The ionospheric parameters in E/F1/F2 layer derived from ionograms" - Page 9 line 199: "The ranges of f0E were respectively

Interactive

comment 
from 1.7 to $4.0 \mathrm{MHz}$ and from $85 \mathrm{~km}$ to $100 \mathrm{~km}$." I suggest to change to: "The ranges of f0E were respectively from 1.7 to $4.0 \mathrm{MHz}$ and its virtual height (h'E) from $85 \mathrm{~km}$ to $100 \mathrm{~km}$."

Please also note the supplement to this comment:

https://www.ann-geophys-discuss.net/angeo-2019-72/angeo-2019-72-RC1-

supplement.pdf

Interactive comment on Ann. Geophys. Discuss., https://doi.org/10.5194/angeo-2019-72, 2019. 